Methods of preparing the chlorates of sodium and potassium, of purifying aluminium sulphate, of manufacturing persulphates, alkali bichromates, potassium permanganate, sodium hyposulphite, white lead, vermilion, etc., in the electrolytic way, are placed before the reader in a most attractive manner, so that as we proceed we are inspired with a desire to repeat these experiments, but having previously carried out similar schemes for most of the substances mentioned we find pleasure in corroborating the statements of the author, with an invitation to others to embark in this field of investigation.

The second section considers the application of the current to organic substances. The author credits Davy with having been the first chemist to venture into the field, but adds that Kolbe, Wurtz, Bourgoin, Walker, Miller, Weems, Berthelot and others made researches in this direction. Your reviewer would include the name of Mulliken in this list. The efforts of these men, bestowed upon the aliphatic acids and their salts, have been most fruitful, but the author of the work before us is content, and naturally enough, to give certain generalizations and deductions from the pen of Bourgoin, and then branches forth upon the synthesis of alcohol by Lapeyriere in 1880, with brief mention of that of Eisenmann, the decolorization of bark liquors, electrolytic tanning, etc. This section may be said to be entirely technical, but it, as well as the first section, merits the attention of chemists generally, for both contain much valuable matter, concisely expressed and highly suggestive.

Edgar F. SMith.

Electro-Metallurgie. Voie humide et voie sèche. Par Ad. Minet. Paris, Boulevard St. Germain, 120, Masson et Cie.

The author first defines electro-metallurgy, describes different types of electrical apparatus, and reviews the various laws relating to electrolytes, then outlines the precipitation of copper, lead, silver, bismuth, cadmium, mercury, gold, platinum, iridium, tin, antimony, iron, nickel, cobalt and zinc, giving with each the most suitable composition of bath, the proper current density, the regeneration of the liquors and other data valuable to those engaged in electroplating.

The second section of the book, devoted to electro-metallurgy in the dry way, is most interesting. The metals considered are aluminium, magnesium, sodium, potassium, lithium, calcium, strontium, barium and zinc. A short historical sketch precedes the working conditions laid down for each metal. Taking aluminium as an example, there first appears a general outline for its isolation from the double fluoride of aluminium and sodium; then follow a description of the methods proposed by Minet, Heroult and Hall, with directions as to choice of electrolyte, including its physical properties, as well as the mode of regeneration, and also the electromotive force necessary for the decomposition of the various salts, and hints as to the nature and shape of the vessel intended to carry the electrolyte.

Students of chemistry will read this section with pleasure and profit, and lay aside the volume with the conviction that it brings little which can be criticised and a very great deal which will be helpful to all who wish to pursue this line of study further.

\section{A Manual of Quantitative Chemical Analysis.}

By E. F. LADD, B.S., Professor of Chemistry in the North Dakota Agricultural College, and Chemist to the Government Experiment Station, Fargo, N. D. New York, John Wiley \& Sons. 1898.

"This little manual is intended for the use of beginners in quantitative analysis. The methods have been selected to advance the student from the simple analysis to the more complex and difficult, and when he has completed the course as laid down here he will be in a position to intelligently use and interpret the advanced works of Fresenius, Crookes and the Encyclopædias." A book which will give a few simple examples illustrating the principles of analytical chemistry can be used with advantage by those who only wish a general idea of chemistry; but it is doubtful whether such a book is useful to one who expects to go more deeply into the subject. He would either have a very slight knowledge of the subject or would have to repeat the work in a more thorough manner. 